\title{
REVIEW
}

\section{Work shift duration: a review comparing eight hour and 12 hour shift systems}

\author{
Lawrence Smith, Simon Folkard, Phil Tucker, Ian Macdonald
}

\begin{abstract}
Objectives-Shiftwork is now a major feature of working life across a broad range of industries. The features of the shift systems operated can impact on the wellbeing, performance, and sleep of shiftworkers. This paper reviews the current state of knowledge on one major characteristic of shift rotas-namely, shift duration. Evidence comparing the relative effects of eight hour and 12 hour shifts on fatigue and job performance, safety, sleep, and physical and psychological health are considered. At the organisational level, factors such as the mode of system implementation, attitudes towards shift rotas, sickness absence and turnover, overtime, and moonlighting are discussed.
\end{abstract}

Methods-Manual and electronic searches of the shiftwork research literature were conducted to obtain information on comparisons between eight hour and 12 hour shifts.

Results-The research findings are largely equivocal. The bulk of the evidence suggests few differences between eight and 12 hour shifts in the way they affect people. There may even be advantages to 12 hour shifts in terms of lower stress levels, better physical and psychological wellbeing, improved durations and quality of off duty sleep as well as improvements in family relations. On the negative side, the main concerns are fatigue and safety. It is noted that a 12 hour shift does not equate with being active for only 12 hours. Conclusions-There can be considerable extension of the person's time awake either side of the shift. However, the effects of longer term exposure to extended work days have been relatively uncharted in any systematic way. Longitudinal comparative research into the chronic impact of the compressed working week is needed.

(Occup Environ Med 1998;55:217-229)

Keywords: shift duration; health; sleep; 12 hour shifts

In response to economic, technological, and social pressures a 24 hour organisation of the workplace is now common. This requires the workforce to accept and become adapted to many different forms of shiftwork schedule. However, the adverse effects of shiftworking are well chronicled..$^{1-3}$ They include biological disruption to physiological processes, including the sleep-wake cycle ${ }^{4}$; the impairment of physical health and psychological wellbeing ${ }^{35}$; problems with alertness, performance, and safety, ${ }^{67}$ and lastly, interference with social and domestic life. ${ }^{89}$ The extent to which shiftwork affects the individual person depends largely on the job being done, characteristics of the individual, the organisational and social environments, and features of the shift system. This potential impairment to functioning exists because daily rhythms in human physiology, hormone concentrations, biochemistry, and behaviour have become entrained to the most reliable and predictable cyclic changes in the physical and social environments. Under shiftworking conditions, and especially when required to work at night, the components of this system of circadian rhythms are regularly disrupted as a result of having to alter the activity-rest cycle.

Many thousands of shiftwork schedules are known to be in operation world wide but consideration of shift duration highlights two common categories of shift systems, each with numerous permutations, designed to provide 24 hour cover-namely, systems comprising threexeight hour shifts or two $\times 12$ hour shifts. Twelve hour rotas represent a compressed working week which has been defined as: "Any system of fixed working hours more than eight hours in duration which results in a working week of less than five full days of work a week". ${ }^{10}$ Conversion to a compressed working week is often considered because of the perceived potential benefits for production and morale, reduction of sickness absence, ${ }^{11}$ and the convenience of having extra time off work. ${ }^{12}$

A recent Bulletin of European Studies of Time ${ }^{13}$ considers many of the issues surrounding the compressed working week. Schedules involving shifts greater than eight hours and fewer than five full days at work (including 12 hour schedules) are discussed somewhat interchangeably. That is, a rather broad brush approach is generally taken. This paper also intends to take a broad view as it reviews the shiftwork literature that compares the impact of eight and 12 hour 
shift rotas on the sleep, health, performance, and safety of the people concerned. In doing so we cite information ranging from anecdotal evidence to field based research. The overriding objective is to provide the interested reader with a comprehensive overview of the debate on shift durations.

This review aims to provide evidence from a wide range of information, much of which is inaccessible to many interested in the area of effects of working time. The sections which follow consider information relating to the implications of eight and 12 hour shifts for: (a) fatigue and performance in work; (b) safety; (c) sleep, physical health, and psychosocial wellbeing; (d) system implementation, shiftworker attitudes, preferences, and morale; (e) absenteeism and turnover; and $(f)$ overtime and moonlighting.

\section{Method}

The primary sources of information were research project reports and theoretical or research based peer reviewed journal papers. These were found by extensive manual and electronic literature searches conducted on: the Internet; the United Kingdom Health and Safety Executive CD-ROM database accessed at the Health and Safety Executive Library, Broad Lane, Sheffield, United Kingdom; MedLine CD-ROM database accessed on the internet; Psych-Lit CD-ROM database accessed on the Internet; and the social sciences citation index. Also, authors of reports and articles not widely available were contacted. ${ }^{13 a}$

\section{Results}

Much of the research and commentary comparing eight and 12 hour systems originates (although not exclusively) in two major sectors of industry. One source has been the health service where the best type of shift system to promote patient care and staff satisfaction has been the subject of considerable debate in the literature related to healthcare shiftwork, especially in the United States. The other source has been the nuclear industry where safe operations are the prime concern and the possible effects induced by fatigue of longer workshifts need to be carefully examined.

Twelve hour systems are popular with shiftworkers because they compress the working week and offer greater opportunity for time away from work. As we shall see, after the introduction of 12 hour shifts some studies have reported benefits in positive attitudes about travel to work and time off duty, improved staff morale, and reduced sickness absence. ${ }^{14}{ }^{15}$ However, unfavourable outcomes have also been reported after the introduction of 12 hour shifts. For example, reduction in quality of patient care and dislike of the shift have been cited as major problems in hospitals. ${ }^{16} 17$

The major arguments against 12 hour shifts tend to revolve around the concern that they promote fatigue and compromise alertness and performance, thereby reducing operational efficiency or safety. ${ }^{18}$ Consequently, the worktime research literature cautions against longer work shifts, especially 12 hour night shifts, where public safety is a main consideration. However, the research evidence on compressed working weeks tends to be less supportive of this position. For example in a comprehensive review and meta-analysis of empirical studies into the effects of compressed working weeks, it has been concluded that, if anything, the impact of such scheduling is beneficial. ${ }^{19}$ It was shown that compressed schedules brought moderate decreases in sickness absence, small increases in productivity, large increases in schedule and job satisfaction, but also moderate increases in fatigue.

From just these introductory examples it can immediately be seen that the evidence from research comparing eight hour and 12 hour shifts can be complex and possibly contradictory. The following sections will consider the evidence for differences between eight hour and 12 hour systems and try to draw conclusions about their implications for several aspects of shiftworkers' lives and employing organisations.

\section{FATIGUE AND JOB PERFORMANCE}

Earlier comparisons of job performance were not favourable to the 12 hour systems. The British Industrial Fatigue Research Board reported apparent changes in productivity after the reduction of shift times from 12 hours to eight hours at a steel mill between 1910 and $1914 .^{20}$ Production details were obtained for two years before and two years after the change to the three $\times$ eight system at the steel works. A gradual decrease in output over the 12 hour period was reported. After no immediate change in output in the first two months of the eight hour rota, there followed an increase in productivity which reached a peak 13 months after the reduction in shift hours before starting a gradual decline. Vernon ${ }^{20}$ concluded that this represented a significant increase (about 18\%) in output which could not be masked by the subsequent decline.

Osborne $^{21}$ examined differences in production output and fatigue at a munitions factory relative to eight hour and 12 hour shifts. For work which was self paced the equivalent amount of work completed in 100 minutes on a 12 hour system was completed in 80.5 minutes on the eight hour system. On all measures there was an apparent advantage in terms of output on the eight hour compared with the 12 hour schedule-for example, there was an increase in output, of shells manufactured per hour, of $6.5 \%$ for an overall average reduction of 20.20 hours per week. A considerable drop in output was found over the last four hours of a shift, a decrease that was especially prominent on 12 hour shifts. Osborne ${ }^{21}$ concluded that output was more capable of being sustained on eight hour shifts. So, both of these early studies did not support longer shifts.

Fatigue and decreased alertness towards the end of a 12 hour shift can be a real concern and should be borne in mind when such systems are implemented, especially when the job being worked is highly monotonous and sedentary such as monitoring VDU screens, or requires 
continuous heavy physical activity. ${ }^{10}$ Fatigue and disruption to family and social life have also been suggested to outweigh benefits in job satisfaction and the delivery of care in a hospital setting. ${ }^{22}$ This is unexpected as one of the supposed benefits of 12 hour systems is an increase in time available for social, family, and leisure pursuits. Nevertheless, it is not a unique finding, with other researchers reporting similar social disruption on 12 hour systems. ${ }^{23}{ }^{24}$

Performance of nurses has been widely studied relative to eight hour and 12 hour rotas. Often, the primary concerns of these studies are the allocation of human resources and the effective, economic provision of care. Several studies have concluded that there are generally no differences between the two systems in fatigue or critical thinking performance, ${ }^{2526}$ and one study concluded that 12 hour shifts would contribute to optimising staffing resources. ${ }^{27}$ Ugrovics and Wright ${ }^{27}$ reported that the last hour of the first 12 hour shift was associated with an increase in fatigue and drop in concentration, although Fields and Loveridge $^{25}$ concluded that fatigue increases significantly over the shift, irrespective of shift duration. Fatigue and job performance may not necessarily be linked. Mills et $a l^{28}$ found that whereas 12 hour shifts were associated with increased fatigue over the shift as well as an increase in performance errors on grammatical reasoning and medical record reviewing tasks, they did not affect overall levels of job performance.

Williamson $e t a l^{29}$ investigated the effects of 12 hour shifts on the work quality and productivity of computer operators. They found that a change from eight hour to 12 hour shifts was accompanied by improved wellbeing, especially psychological health and reduced tiredness throughout the work period. There were no apparent costs in terms of job satisfaction or productivity as a result of the 12 hour rota. Even under conditions of high physical workload, mining shiftworkers have been reported to show no differences in levels of fatigue between eight hour and 12 hour shifts. ${ }^{30}$

Work efficiency was deemed to have shown an improvement as a result of changing to 12 hour schedules in the study of Wilson and Rose $^{31}$ of chemical and petroleum industry shiftworkers. Several contributing factors were apparent. These were reported to include: improved shift handovers, decreased turnover, and better employee attitudes and communications. A decrease in the number of shift changeovers reduced the margins for error with better continuity of communication between those starting and those finishing work. An area of substantial improvement in communication was between production and maintenance workers. The 12 hour shifts allowed operators to make equipment ready for the maintenance crew and pay more attention to repair or servicing because the same crew had to restart the equipment.

However, communication may not always benefit. Breakdown can occur in the interactions between shiftworkers and management or administrators. There can also be communica- tion problems between shifts after three or four days away from work. ${ }^{31}$ Under eight hour systems workers can be in the plant for 21 out of 28 days whereas most of the 12 hour rotas studied required only 14 out of 28 days at work. On eight hour shifts workermanagement overlap at the plant was around 10 days per month whereas on 12 hour shifts the overlap was five days per month. The long breaks between work periods were also a potential source of serious difficulties. The number of consecutive rest days ranged from two to eight on some 12 hour schedules. The former eight hour schedules provided much shorter and less frequent time away from the plant, the longest period away being three days, which happened only once every 28 days. One consequence was that on 12 hour rotas there was a greater reliance on written communications. Shift teams relieving one another after long breaks were seldom in contact with one another and thus the efficient transfer of information about the plant or a process can be impeded. So, one disadvantage of the increased potential for rest and recuperation may be the greater need for work reorientation on return from long breaks.

Evidence from other studies of eight hour versus 12 hour rotas ties in with this suggestion. Compared with those on eight hour shifts Johnston et $a l^{\beta 2}$ reported that nurses on 12 hour shifts tended to be less alert. They also found that the 12 hour shift nurses showed increased errors and faster performance (a classic speedaccuracy trade off) in a letter cancellation task and decreased accuracy on a choice reaction time task. These effects seem to be acute and associated with the beginning of the first 12 hour shift after a block of rest days; suggesting the need to consider the appropriate scheduling of work tasks in the reorientation period after long blocks of rest days on 12 hour rotas.

Smiley and Moray $^{33}$ noted that it is also important to take into account the sequencing of shifts, the way they rotate, and rest days available as well as overtime practices; all of which may impact on alertness during the shift, performance, and the experience of fatigue. For example, Baker et $a b^{34}$ cited a study which showed an interaction between the number of consecutive days worked per week over successive weeks and duration of shift. Compared with an equivalent number of successive eight hour shifts, there were significant decreases in productivity on five to seven consecutive 12 hour shifts. After four weeks of six or seven consecutive 12 hour shifts there were even greater decrements in productivity. Such findings strongly militate against the use of more than three or four successive 12 hour shifts in a compressed schedule.

Todd et $a l^{\beta^{5}}$ and Reid et $a l^{\beta^{6}}$ have also gathered some unfavourable findings. In one investigation they compared the effects of eight hour and 12 hour shifts on patient care, work attitudes, and cognitive functioning. ${ }^{35}$ They found that there was lower quality of care, less direct patient care, especially in the later part of the day, that nurses' ability to study decreased, and that 12 hour shifts were not universally 
liked. Acceptance of the longer shifts was generally related to lifestyle considerations. No differences in cognitive performance was found between eight hour and 12 hour shifts. The authors suggested that there was no advantage in staffing levels or the reduction of shift handovers and therefore little justification in their introduction.

Bowers-Hutto and Davis, ${ }^{37}$ in a study of nurses on 12 hour shifts, indicated that several reported impaired judgement, poorer clinical decisions, and slower response times when on 12 hour shifts. Thompson ${ }^{23}$ found that nurses on eight hour shifts started their work periods more alert than those on 12 hour shifts after completing several simple performance tasks. In a later study Reid et $a l^{36}$ also reported a negative impact of 12 hour shifts on the delivery of patient care. A significant reduction in direct patient care was found in conjunction with an increase in unofficial work breaks. The results were suggested to reflect a pacing effect for nurses facing 12 hours on duty.

Other researchers have suggested that the effects of extended shifts may be obscured by other factors - such as motivation. This may be the reason why, as was noted earlier, fatigue and job performance are not automatically linked. Washburn ${ }^{26}$ reported that although fatigue increased towards the end of each shift, performance tended to increase also, possibly as a result of an increase in compensatory task effort. A comparison of police officers on eight hour and 12 hour rotas showed large decreases in subjective alertness from the beginning to the end of eight hour shifts and 12 hour night shifts, but no such effect for 12 hour days. ${ }^{38}$ The contrast was thought to be a result of the overwhelming preference of the officers for the 12 hour system. Another suggestion was that their 12 hour day shift ended at 1900 close to the time of the acrophase in alertness levels and that the natural increment in alertness compensated for any on shift effects.

In a recent paper Rosa ${ }^{18}$ considered issues surrounding extended workshifts and their links to excessive fatigue. His arguments were based mainly on consideration of the relation between 12 hour shifts and the build up of fatigue. One point of concern is that the potential for an increase in fatigue is particularly salient when shiftworkers are asked to cover a portion of a subsequent shift, or even double up on their shifts to cover for absences or some mutual arrangement with shift colleagues. Twelve hour shifts can even run to 24 hours of work in some situations. For example, on offshore drilling platforms at the transition from a week of 12 hour nights to a week of day shifts the shiftworker typically worked the last 12 hour night immediately followed by a 12 hour day before a scheduled break for sleep. ${ }^{39}$ Thus, it could be argued that extended workshifts could have negative consequences, not least in terms of increased fatigue and impaired job performance.

\section{Summary}

The evidence on the effects of 12 hour systems on fatigue and job performance is equivocal.
One possible reason for this is that extended work periods are popular with shiftworkers as they compress the working week, and this may increase motivation and stimulate greater effort to reduce any possible detrimental effects of increased fatigue. In such cases some benefits from 12 hour systems may appear. However, the characteristics of the shift rota and the demands of the work performed can have a large impact on this equality of job performance and the possibility of advantage. Therefore care must be exercised in choosing appropriate jobs and systems.

\section{SAFETY}

Examination of the safety implications of 12 hour shifts is particularly keen in relation to industrial processes or services that hold a potential for considerable public harm such as chemical processing, air traffic control, public transport, and nuclear power generation. Despite the increased opportunities for leisure time on 12 hour shifts, the longer working day has the potential to contribute to human error and accidents at work. ${ }^{18}$

The fear of greater accident and injury on 12 hour shifts is not convincingly confirmed by research findings. Northrup ${ }^{40}$ could find no study that conclusively reported such increases on longer shifts; indeed, he found fewer accidents on 12 hour shifts in the steel industry. Wilson and Rose ${ }^{31}$ surveyed 50 locations and also found no reports of increased accidents linked to the 12 hour shifts. It was understood that action had been taken to mitigate the potential for decreased safety. Management acted to emphasise preventive safety measures in response to the fears about possible deterioration in safety performance. Employees also recognised the possible effects of fatigue and these concerns led to greater conscientiousness (it is, however, appropriate to question the longevity of the efficacy of these preventative activities). Several sites reported having their longest periods without injury based lost time: a range from two to 10 million man hours had been worked without a lost time injury after the introduction of 12 hour shifts. One plant reported a $60 \%$ decrease in recorded injuries but the downside to this was a $55 \%$ increase in hazardous incidents which did not lead to injury (although this was also linked to management's increased attention to reporting of hazardous conditions).

In one of few studies that have made an attempt at a direct comparison Lees and Laundry ${ }^{41}$ reported a study of reported accidents in a company that had changed from eight to 12 hour shifts. Their overall conclusion was that minor and moderate injuries (without lost time) decreased significantly in the 10 years after the change to the 12 hour shift regime compared with 10 years of accident data before the change. More recently, Pollock et $a l^{42}$ reported a comparison of injury patterns on eight and 12 hour shifts in a petrochemical plant and a fertiliser producing company. Their broadly based results showed that neither company showed a significant change in frequencies of injuries after implementing the 12 hour 
shift. Where severity was examined it was reported that after the change to 12 hour shifts there was a higher percentage of more serious injuries and a lower percentage of minor injuries on 12 hour shifts in the petrochemical company. No differences emerged for the fertiliser plant. The authors suggested that 12 hour shifts may have differential effects in different companies because of the nature of the work, the characteristics of the workers, and the environment. Part of the explanation may also lie in a change to a more rigorous safety culture within an organisation.

Studies in nuclear power plants which have converted from eight hour to 12 hour shifts have found no significant decreases in productivity nor increases in operator error after the change. ${ }^{43}$ Smiley and Moray $^{33}$ reported that after a seven year period of recording all incidents at a nuclear plant that had adopted 12 hour shifts there was no evidence of a deleterious impact. A possible factor involved in improvements after a switch to 12 hour shifts is the reduction in the number of shift handovers that occur. Indeed, the company management thought that handovers between two crews were an improvement on those for three crews on an eight hour system. Another study at an experimental nuclear reactor examined the effects of changes from an eight hour to a 12 hour rota. ${ }^{44}$ Although no night shift data were collected it was concluded that the 12 hour day shift was a reasonable alternative to eight hour day shifts with respect to safety and job performance. There was a $25 \%$ decrease in error in completing operational logs after the move to 12 hour day shifts. Operators were slightly less alert at the end of their 12 hour shifts compared with the eight hour shifts but there was a significant difference between the two schedules of the performance integrity of the plant on 12 hour shifts. Moreover, supervisors and most operators reported greater work effectiveness associated with the 12 hour shifts. The 12 hour shifts were considered better because only 12 hours was spent away from the plant between successive shifts. Therefore operators remained job oriented to a greater extent than they would with a 16 hour break between successive shifts. Communication at shift handover was reported to be better because on the 12 hour rota shift teams leaving work handed over to the same team it received the plant from 12 hours earlier. In such a high potential hazard industry, optimising the flow of communications between shift crews is clearly crucial. Nevertheless, difficulties can arise as shiftworkers can become out of touch with conditions at the plant. This was highlighted by greater impairments in shift handovers after a block of seven rest days on the 12 hour system compared with after a block of four rest days on the eight hour system.

Not all investigators have come to positive conclusions about 12 hour systems. For example, Kelly and Schneider ${ }^{45}$ examined the performance records of operator error and personal accident at a nuclear power plant relative to eight hour and 12 hour shifts. Their risk assessment suggested a $70 \%$ increase in the probability of an incident with public implications to be associated with the operation of 12 hour shifts. Despite these dire predictions and contrary to the report in the article ${ }^{45}$ the plant implemented a 2-3-2 pattern of 12 hour shifts and it has operated these shifts ever since (personal communication Baker TL). Safety was not compromised and incidents relevant to the public did not increase. Similarly, Rosa and Colligan ${ }^{46}$ considered a decline in alertness and performance during the last few hours of a 12 hours shift and disruption to subsequent sleep episodes problematic at a nuclear plant. However, this is not uncommon, even towards the end of eight hour shifts, and in this case it was concluded by the management that the operational integrity of the plant remained unchanged under the 12 hour schedule. The increased number of rest days on 12 hour systems may compensate in the long run for acute sleep disruption.

Rosa $^{47}$ also examined control room operators at a continuous processing plant. After seven months on a 12 hour schedule, decrements in alertness and performance as well as a mild to moderate sleep debt were found compared with the original eight hour system. A three to five year follow up of these shiftworkers showed persistent decrements in performance and alertness attributable to 12 hour shifts and a reduction in sleep duration after night shifts. There was, however, little deterioration in performance or alertness across the working week, which suggested day to day recovery from the extended work period. Workers may be motivated to tolerate a 12 hour system because of the potential social gains the schedule allows. ${ }^{47}$ In another study at a natural gas facility Rosa and Bonnet ${ }^{48}$ reported that after 10 months adaptation to a new 12 hour schedule there were decrements in performance and alertness attributable to the last hours of the extended work shift. There was also disruption to sleep across the working week that was most pronounced for the 12 hour night shifts. As a result it was suggested that extra caution be exercised in the scheduling of critical activities on 12 hour shifts, especially at night.

The main concerns for safety and human performance and guidelines from the US Nuclear Regulatory Commission were reviewed by Gould ${ }^{49}$ who discussed the safety implications of 12 hour shifts in nuclear power plants. Several recommendations were suggested. Firstly, 12 hour schedules should be arranged so that overtime is covered without holding over a 12 hour shiftworker or calling in a worker who had fewer than three rest days after four consecutive 12 hour shifts. Secondly, the round trip to and from work should be less than three hours a day because any longer than this would reduce the opportunity for adequate sleep. Thirdly, active efforts should be made to reorient the workers after breaks of longer than four days to help counter the forgetting factor. Fourthly, to help reduce fatigue shorter and more frequent breaks may be more appropriate than long ones. It was also reported that 12 hour shifts have been implemented at nuclear power plants with no evidence of a reduction in 
job performance nor increase in error rates. Moreover, he stated that there could be improvements to communications at shift handover as well as increases in job satisfaction.

\section{Summary}

There seems to be no conclusive evidence that extended work shifts compromise safety from the point of view of increased accident rates, or from reduction in job performance, or increase in error rates. However, in part this may be due to increased emphasis on preventive safety measures in response to the fears about possible deterioration in safety from both management and employees. It is therefore appropriate to question the longevity of the efficacy of these preventive activities. Nevertheless, providing that adequate measures are taken it seems that 12 hour shifts do not automatically induce a significant decrement in safety.

SLEEP, PHYSICAL HEALTH, AND PSYCHOSOCIAL WELLBEING

Sleep and general wellbeing have also been examined for 12 hour systems. Wilson and Rose $^{31}$ noted that shiftworkers reported feeling at least as good, or better, emotionally and physically on 12 hour shifts than on eight hour rotas. Publications on 12 hour schedules offer some support for this contention.

Lees and Laundry ${ }^{50}$ examined archival evidence on workers' health over a 10 year period on eight hour shifts followed by a 10 year period on a 12 hour rota, within a steel plant. The workers reported fewer headaches and problems with digestion and alcohol misuse on the 12 hour schedule. However, there was no difference between the eight and 12 hour rotas of feelings of general malaise or nervous condition. Several other studies in a range of occupations have reported little or no deleterious effect of 12 hour shifts on factors such as physical and psychological wellbeing, stress, and tiredness. ${ }^{30} 51$ Tucker et $a \bar{l}^{2}$ found that, except for levels of alertness, there were relatively few differences between eight and 12 hour systems in health and wellbeing, disruption to sleep, and social life. What differences there were tended to favour (although not exclusively) the 12 hour system. They concluded that compression of the working week into fewer, longer shifts need not necessarily be problematic for the workers and there may be advantages to working 12 hour shifts.

Jaffe et $a b^{3}$ compared three groups of petrochemical workers (dayworkers, shiftworkers on an eight hour advancing (NAM) system, and workers on a 12 hour rota). The eight hour shiftworkers had greater problems with sleep quality, and health complaints, and expressed least satisfaction with time available for personal and family pursuits. The sleep quality problems were attributed to the quick returns in the rota and the direction of rotation of the schedule, which mitigates against the biological clock's natural tendency to delay and thus favours delaying systems. Jaffe $e t a l^{3}$ concluded that other features of the shift schedule are more critical than duration off duty in explain- ing disruption to sleep, health, and social life (see also Knauth ${ }^{54}$ ).

In their study of police officers Peacock et $a l^{\beta 8}$ found that the 12 hour system provided opportunity for better sleep habits than an eight hour system because for $75 \%$ of the 12 hour eight day shift cycle implemented, a normal day-night sleep pattern could be maintained. For physical fitness, the same study reported that officers on the 12 hour shifts were able to achieve higher workloads with less physiological strain. Officers were found to be fitter on the 12 hour rota, possibly because of better sleep patterns, greater regularity in eating habits, and more opportunity for recreational activities. Gadbois and Prunier ${ }^{55}$ studied customs officers and found that those working 12 hour shifts had better health and sleep than did colleagues working six hour shifts. One confounding factor, however, was differences in the kinds of tasks performed. Iskra-Golec et $a b^{6}$ reported a negative impact of 12 hour shifts on wellbeing but suggested that the effects may be moderated by the nature of the job being done.

Chan et $a \bar{l}^{7}$ studied the health complaints, blood pressure, sleep, and sickness absence of female electronics workers who had worked 12 hour shifts for over a year. No serious health problems were evident in these shiftworkers. The only significant differences in symptom prevalence between the 12 hour shiftworkers and a control group of eight hour day workers were complaints of tiredness and headaches.

Hadjiolova et $a t^{8}$ examined cardiovascular strain and shiftwork tolerance in operators in the control room of a chemical plant on 12 hour shifts. After job analysis and time budget assessment the authors concluded that the operators' jobs were suitable for the extended workday schedule. Indeed, the operators strongly preferred 12 hour shifts and even after three years of the rota their subjective ratings of physical and mental demands did not differ from those before the schedule's implementation.

A recent study of the attitudes of nurses towards eight hour and 12 hour shifts has found some advantage of eight hour shifts. ${ }^{59}$ This research considered the social and family consequences for nurses working on these two forms of shift system. Over $40 \%$ of each group reported low satisfaction with their schedule and a desire for its change. Eight hour shifts were viewed more favourably because of lower levels of work strain, better continuity of service, and less disruption to health, family, and leisure life. The impact of schedule type on family and social life was a main moderator of system satisfaction and attitudes towards a change in rota. It was concluded that neither type of shift system was very attractive to the participants because both schedules interfered with family and social responsibilities. However, there seemed to be negative effects of 12 hour shifts on social and family life, precisely those areas that are argued to be improved by such a system..$^{22}{ }^{23}$ The authors noted that these effects were indirect. It was suggested that the effects were due to a need for greater recovery 
(from higher reported adverse health effects and poorer subjective health state on 12 hour shifts), which resulted in the erosion of free time during rest breaks.

Another area of possible difficulty occurs when considering the threshold limits for exposure to environmental stressors and various chemicals in the workplace. Legislation, for example, is normally based on eight hour exposure limits. Recently, Knauth ${ }^{54}$ highlighted this point in recommendations for implementing a shift system and expressed concern about the potential harm of extended exposure to toxic chemicals, and other adverse work conditions - such as noise or heat-that working 12 hour shifts could entail. In this respect researchers have suggested that work conditions and the type of work being done will interact with the schedule and exposure limits should be a main consideration when thinking about implementing 12 hour shift systems. ${ }^{546061}$

Reynolds $e t a l^{62}$ assessed a hearing conservation programme which had been instigated under a three $\times$ eight hour system but now operated under 12 hour shift conditions. From an occupational health position it was found that the existing hearing conservation programme was at best marginal in effect irrespective of type of schedule. It was concluded that the 12 hour system had no impact on the level of effectiveness of the programme.

Individual differences in various personal, social, and environmental factors will almost certainly moderate the impact of a shift schedule. ${ }^{39} 63$ This point is illustrated in the report of one study of chemical industry shiftworkers who found that performance on reaction time, reasoning, visual search, and tapping tasks was poorer on 12 hour than eight hour shifts. ${ }^{64}$ The authors indicated that the results were confounded by the differences in capabilities of the workers on each rota.

Rosa $^{18}$ suggested several rarely studied factors that might exacerbate the potential fatiguing effects of longer work periods. These compounding influences include workplace stressors - such as workload, noise, exposure to toxic chemicals, heat-organisational issuessuch as staffing levels, nature of job tasks, and rest breaks - as well as commuting time and pressures due to domestic and social responsibilities outside work. His overall message is one of cautious introduction of 12 hour systems in concert with careful evaluation of their impact.

\section{Summary}

Much of the evidence suggests that shiftworkers do not have great problems with sleep, health, and wellbeing when working 12 hour compared with eight hour shifts and may even show improvements in these areas. The situation is not entirely straightforward and consideration has to be given to working conditions and the nature of the job, particularly workplace stressors.
SYSTEM IMPLEMENTATION, ATTITUDES, PREFERENCES, AND MORALE

The way a new shift system is introduced to a workforce has a substantial impact on its degree of acceptance. Johnston et $a l^{22}$ for example, reported that nurses in their study disliked the 12 hour system and this attitude may have influenced subjective reporting. However, the overall conclusion was that there were no deleterious effects of the 12 hour rota in terms of tiredness and stress compared with eight hour shifts. In contrast, the success of a 12 hour system for nurses who had worked it for three years was considered to be dependent on how and why the schedule was implemented. ${ }^{23}$ For example, satisfaction with a 12 hour rota was reported where it was introduced to help reduce commuting. In a study on the change from an eight to a 12 hour rota at an oil refinery Conrad-Betschart ${ }^{65}$ pointed out that the shift system design and implementation process had been a neglected area of research. The study showed that employee participation in negotiating the system and changes to conditions related to shiftwork - such as provision of an extra break during 12 hour shifts and improved meal facilities at night - was critical for the acceptance and positive effects of the new schedule. The author argued that the findings confirmed those of other research into the influence of direct participation in the organisation of work scheduling. ${ }^{667}$ There will inevitably be difficulties in getting the full consent of a shift workforce, because no system can suit all preferences. Nevertheless, Conrad-Betschart ${ }^{65}$ suggested that these problems will be transitory if all relevant stakeholders have the opportunity to be involved in the process.

Considering the apparent popularity of 12 hour systems, Smith et $a l^{68}$ posed the question of whether 12 hour shift systems can be a solution to some of the difficulties experienced by shiftworkers in a study of police officers. Few differences were found between 12 hour and eight hour shift groups after a six month trial period. The differences that emerged seemed to be linked to the nature of the implementation of the 12 hour rotas. At one site a flexible 12 hour system was implemented which gave the opportunity to negotiate the timing of work to fit personal circumstances. There was also a later start to the day shift (0715) on the flexible system which seemed to contribute to improved sleep quality after the day shift and the maintenance of alertness on shift. In contrast, these variables decreased for those on the rigid 12 hour system with its earlier start (0600). Daytime sleep durations after night shifts, however, did not show the same benefits. A possible explanation is that coming off the night shift later (at 0715) on the flexible rota means that by the time the shiftworker gets home and goes to bed, the body clock is more geared up for wakefulness and activity than it would otherwise be after the 0600 end of shift. Psychological health was maintained at a stable level on the flexible system but deteriorated in officers on the rigid system. The situation was not simply one of eight versus 12 hour shifts 
but rather of how features of a rota are changed and how a new shift system is implemented. Flexibility and opportunity to exert some control over working time seems to be an increasingly important factor in how a rota is accepted by a workforce and impacts on individual people. ${ }^{69}$

Suter ${ }^{70}$ commented on the introduction of 12 hour shifts at an American nuclear power plant. Cooperation with those directly affected (including union representation) was considered vital to the success of implementation. Indeed, shiftwork research has suggested that employee participation and sense of control is crucial. ${ }^{69}$ Wilson and Rose ${ }^{31}$ reported favourable responses to 12 hour rotas as a result of employees choosing the systems-generally perceiving the benefits to outweigh the costs. At one plant where the schedule was imposed, worker reactions were negative to such an extent that the old three $\times$ eight hour schedule had to be reinstated. Peacock $e t a l^{88}$ concluded that there were no disadvantages of a 12 hour system with an eight day cycle when compared with an eight hour system with a 12 day cycle for sleep patterns, physiological and psychological effects, or subjective measures of alertness. They reported overwhelming support for the 12 hour system from various operational and social standpoints but did suggest the need to monitor whether attitudes might change in the longer term once the honeymoon period was over. Tepas,${ }^{71}$ on the other hand, has suggested that condensed work weeks may gain in popularity as experience of them in the work sector increases.

In many of the studies on 12 hour schedules the shiftworkers tended to prefer them to eight hour shifts. The main rationale for preferring 12 hour rotas is that compressed working weeks allow more free time away from work and this can have positive spill-over effects on domestic life. For example, BartonCunningham $^{72}$ found that younger married 12 hour shiftworkers were more satisfied with their family relations. Others have commented on this aspect of compressing the working week $^{27}$ (see also earlier sections on fatigue and sleep, physical health, and psychosocial wellbeing). One caveat to this position (untested at this point) is that some shiftworkers may find it difficult to adjust to spending more time with their families. Research has also highlighted a difference in perceived benefits between shiftworkers and their partners. Wallace et $a l^{4}$ reported that the partners of shiftworkers who had changed from an eight hour to a 12 hour system saw no particular advantage in the change for family and personal life, whereas the shiftworkers themselves were strongly in favour of the change to 12 hour shifts. Attitudes towards 12 hour shifts may also vary according to the nature of the work task being carried out, level of responsibility, and working environment. Smiley and Moray ${ }^{33}$ noted that maintenance personnel showed a greater preference for 12 hour shifts than control room supervisors. One reason for this was the supervisors' feeling of an increased burden of responsibility for plant safety on longer shifts. Another argu- ment for the difference in attitude was that maintenance crews' work was more varied, self paced, and involved more physical activity whereas operators and supervisors performed largely sedentary monitoring tasks.

\section{Summary}

It has been suggested that part of the reason that 12 hour systems have not been shown to have a detrimental effect on job performance or safety is that in general the shiftworkers are in favour of the systems and may make efforts to accommodate them. The corollary to this hypothesis must be that the way the system is implemented is of great importance to the attitudes, preferences, and morale of the work force and ultimately to the success of the implementation. It is important to involve the work force in the design and implementation process so that not only will it have their support, but the differences in their work and attitudes to that work will be registered.

\section{ABSENTEEISM AND TURNOVER}

Given the above arguments it would be reasonable to assume that those shiftworkers who have a positive attitude towards their work schedule would be less likely to be absent from work, leave work, or change to a day job within work. Contrary to prevailing expectation Ivancevich $^{73}$ found no difference in rates of absenteeism between compressed working weeks (four to 40) and standard five day weeks. Considering sickness absence and frequency of medical consultations, Nachreiner et $a l^{4}$ also found no significant differences between eight and 12 hour shiftworkers. Others have noted that decreases in absenteeism were thought to be one of the benefits of introducing 12 hour schedules but improvements were only found in six out of 50 sites examined and only one of these improved significantly. ${ }^{31}$ There seemed to be a "floor effect", because the companies reported no real problems with sickness absence before the change to 12 hour rotas. The consensus was that 12 hour shifts did not increase rates of sickness absence. A similar conclusion was drawn more recently by Williamson $\mathrm{et} \mathrm{al.}^{29}$ They reported that a change to 12 hour shifts for computer operators had no significant ill effects on factors related to personnel-such as absenteeism and staff turnover. Turnover of both job leavers and transfer from shiftwork to day work has been reported to remain stable on 12 hour systems. Wilson and Rose ${ }^{31}$ reported general improvements on both counts after the introduction of 12 hour rotas at 50 industrial plants. Employee morale showed improvements in every location surveyed and it was viewed as the main benefit accrued by moving to 12 hour shifts. Shiftworkers thought that many of the onerous aspects of their work had been removed and they were more satisfied with their employer and schedule.

Enthusiasm for the rotas may, however, divide along age lines. Older workers had less favourable attitudes and lower support for the 12 hour rotas. Age may have also been a confounding factor in an article comparing 
health issues and absenteeism in eight and 12 hour shiftworkers. ${ }^{75}$ The findings suggested that 12 hour workers (who were older) had higher rates of absence, higher injury rates, and had higher levels of sickness and intoxication. Older people tend to have more ill health and it is, perhaps, not surprising that an older group of shiftworkers experienced greater difficulties with their 12 hour shift rota. However, in a more recent study Keran et $a l^{6}$ reported no interaction between age and shift duration on physical and psychological measures. Decreased turnover was also a feature of the positive outcome of a change to 12 hour shifts in the study of Conrad-Betschart. ${ }^{65}$ The study reported that an increase in the supply of applicants was a persuasive factor in the permanent introduction of the 12 hour system. Interestingly, a less positive evaluation of the 12 hour rota was found among older workers. ${ }^{65} \mathrm{It}$ was suggested that this was, in part, the result of the new schedule making some forms of moonlighting more difficult. Finally, it may be the case that any decrease in absenteeism found on a 12 hour regime is an artefact of having fewer workdays to be absent from, a point well made by Hoekstra et al. ${ }^{77}$ This, of course, could also account for reported drops in reporting of accidents ${ }^{41}$ and thus apparently improved safety.

\section{Summary}

In general absenteeism and turnover did not increase with 12 hour systems. However, older workers may find it more difficult to deal with those rotas.

\section{OVERTIME AND MOONLIGHTING}

Work effectiveness, safety, and wellbeing are at risk of deterioration as a result of overtime practices compounding potential difficulties arising from a shift schedule. A primary concern is the possible impairment to alertness and performance that may be associated with fatigue from excessive hours on duty. Although $\operatorname{Rosa}^{18}$ points out that overtime has rarely been associated with safety issues or accidents, the extension of the working day through scheduled and unscheduled overtime is an area that requires investigation from both a health and safety perspective.

There may be problems with adequate staffing despite a potential reduction in unscheduled overtime costs as a result of moving to 12 hour schedules. For example, there may be difficulty in filling unscheduled shift vacancies. Contributing factors could include understaffing, existing overtime schedules, difficulty in contacting employees during their rest days, and the scheduling of safety meetings for the first day of a block of rest days. One plant in the study of Wilson and Rose ${ }^{31}$ reported a decrease in unscheduled overtime from around $7 \%$ on the old eight hour schedule to just over $4 \%$ in the first year of the 12 hour shifts. This reduction was attributed to a combination of four causes. Firstly, absenteeism decreased; secondly, 12 hour shifts generally eliminated the need to hold an operator over from their previous eight hour shift when plant downtime lasted nine to 10 hours; thirdly, on eight hour shifts a long shutdown meant three shifts were involved whereas there were only two on the 12 hour rota-reducing the possibility of errors and subsequent overtime; and lastly, additional operators were employed to facilitate training which meant less need to call employees in to work overtime. Nevertheless there is potential for difficulties to arise should shiftworkers have to be called in from their rest days or be required at the end of a 12 hour shift to carry over into the next to cover an unexpected absence.

A report for the Nuclear Regulatory Commission (NRC) in the United States considered the issue of overtime. ${ }^{34}$ It was suggested that when overtime is scheduled its combination with longer shifts may result in shiftworkers' sleep and recovery time becoming depleted. More of a problem is unscheduled overtime which is potentially more disruptive as it increases the difficulty in organising sleep, recovery, and social regimens. ${ }^{18}$ It has been suggested that although 12 hour rotas may result in less overtime per employee per year problems could arise because overtime procedures have often been designed assuming an eight hour shift system. ${ }^{34}$ Where there is no relief crew overtime is typically covered by calling in operators on their days off, to comply with NRC recommendations on daily limits on hours worked. A consequence of this is that effort must be put into protecting rest days and evenly distributing overtime. One recommendation is for overtime to be voluntary rather than mandatory, but there are limitations to this option. Shiftworkers may underestimate or ignore the number of hours they have been awake before working the overtime. Some shiftworkers will inevitably volunteer for, and work excessive hours. Others may completely refuse to work any overtime. The dissemination of more information about the effects of shiftworking and long work hours would enable informed choices to be made about working overtime. This, combined with organisational procedures to check imbalances in the distribution of overtime, could contribute to a lower average impairment for shiftworkers as a whole. The implications of overtime for safety at nuclear power stations were presented more recently by Baker et $a l^{78}$ who examined the relations between overtime worked by operators, technical staff, and maintenance staff and safety incidents. The analysis suggested that safety incidents were most strongly associated with the average annual overtime worked by control room operators. Operator fatigue as a result of this longer working time was suggested to have contributed to safety incidents rather than a reduction in operational integrity of the plant because the overtime activity of the technical and maintenance crews did not show any strong association with the incidents.

A further implication of larger blocks of days off from work is the opportunity for shiftworkers to moonlight. Financial motives may well tempt shiftworkers to take up a second (and even third) job during the period designated for rest and recuperation. Twelve hour shifts could 
contribute to moonlighting through the availability of greater amounts of leisure time and the potential for boredom as a by product of the longer periods away from work. Colligan and Tepas ${ }^{79}$ found that $25 \%$ of 12 hour system shiftworkers were moonlighting. Their concern was that moonlighting may involve the extension of work activity beyond 12 hours and inevitably results in many people returning to work, possibly the night shift, already tired from their extramural activities.

\section{Summary}

The issue of overtime is an area of some concern with 12 hour shift systems. This is because of the potential impairment to alertness and performance that may be associated with fatigue resulting from excessive hours on duty. Therefore, care must be taken to design overtime staffing around the system involved, so that, for example, procedures left over from eight hour systems are not used. Another problem is that the opportunity for moonlighting may also increase with a 12 hour system again with possible consequences of fatigue resulting from excessive hours of work.

\section{Discussion}

Existing knowledge about the extent, nature, and effects of shiftwork allows several general points to be made. Firstly, for better or worse, shiftwork is here to stay. For example, health care, supply of food, and power generation will always be required 24 hours a day. Secondly, to provide continuous cover some form of shift system must be employed. This often results in disruption to the worker because it conflicts with our evolutionary development as diurnal creatures (primarily active during the day, inactive at night). Thirdly, a shift system can have a considerable impact on the people having to work it. This impact may manifest itself in terms of sleep, health, and social disruption, as well as on job performance and safety. Fourthly, these potential effects of shiftwork will depend to varying degrees on the nature of the job-for example, sedentary, monitoring of a control panel, or active physical workpersonal characteristics of the individual-for example, a favourable predisposition to night work or effective coping skills - and features of the system worked-for example, direction and speed of rotation, duration of shifts, and number of consecutive shifts of the same kind. The primary focus of this paper has been the implications of 12 hour shifts for both the individual worker and the organisation.

This paper has considered the influence of duration of the shift on shiftworkers' general wellbeing and effectiveness. Evidence on the relative impact of the two main organisations of shift duration within a shift system has been presented-namely, the effects of rotating eight hour and 12 hour shift rotas on sleep, health, and performance, as well as implications for the organisation. Perhaps the most important point to be made is that the research findings are largely equivocal with both costs and benefits occurring as a consequence of working 12 hour shifts. ${ }^{10}$ The arguments for and against implementation of such shifts can be roughly categorised into two broad areas.

On the positive side, there is a motivational and attitudinal aspect to the acceptance of 12 hour rotas, and self rated stress levels may be considerably reduced. Also there can be high employee acceptance and satisfaction with the system, reduced staff turnover, and improved off duty durations of sleep and sleep quality. Perceived advantages of 12 hour schedules can include improvements in several areas of shiftworkers' lives. Family relations may be enhanced because there is more time for family and friends and more frequent weekends off. Thus, social activity and involvement can be increased. Fewer journeys to and from work can mean savings in the costs and strain of travel. Both physical and psychological wellbeing may benefit. Shiftworkers have reported better appetite and a sense of feeling healthier. ${ }^{29} 3853$ The 12 hour system can also have benefits in better communication at shift handovers. It is also likely that the acceptance of a 12 hour rota by a workforce already holding a favourable attitude towards it will be increased by the opportunity for direct participation in the organisational decision and implementation process.

On the negative side, the main concerns are about effects of fatigue and safety. Although 12 hour rotas tend to be popular with shiftworkers, where there is a high workload their introduction should be the subject of careful scrutiny because of the potential for a build up of fatigue. ${ }^{1864}$ The follow up study of Rosa ${ }^{47}$ which showed persistent alertness and performance decrements on 12 hour shifts, adds to the note of caution. Indeed, it should be emphasised that a 12 hour shift does not usually equate with only being active for 12 hours. There can be considerable extension of the person's time awake on either side of the shift as a result of factors such as sleep curtailment, a long journey, meetings arranged after a shift, and scheduled and unscheduled overtime. There are other disadvantages. Shiftworkers may have to spend long hours on their feet. There may be limitations to educational and other leisure activities. Days off can become boring if a partner works and spending may increase during longer rest breaks. It is also possible that spouses may not like 12 hour schedules even when shiftworkers strongly favour them.

In their study of 50 plants where the range of time that 12 hour rotas had been implemented was four months to five years, Wilson and Rose $^{31}$ noted that the effects of longer term exposure to extended working days had not been thoroughly investigated in any systematic way. Many studies have only examined the replacement of eight hour schedules by 12 hour ones in the short term (although there are exceptions - for example, Lees and Laundry ${ }^{41}$ ). There is a need for research that examines the impact of 12 hour shifts once the euphoria of the honeymoon period has ended..$^{18}$ It is possible that as workers become used to the 12 
hour rotas, new problems will emerge in the long term.

One point should be made about some of the papers used for this review-for example, the article by Wilson and Rose ${ }^{31}$ which has been cited several times during the course of the review. It must be said that the paper is largely anecdotal and unsystematic in its approach. No apology is made for using it as it still contains much useful information. It must not be forgotten that a main purpose of research is to help form decision making and policy that will have a very real impact on some peoples' lives. If we do not listen to their accounts we not only miss out on a large body of information which could inform our theoretical positions but we also lose the opportunity to externally validate the conceptual models on which we base those theoretical positions. Nevertheless, although such papers are valuable it should be recognised that they can only progress the argument so far.

Most evidence cited stems from field research which attempts to instil a more systematic and rigorous approach but still maintains ecological validity. Although providing insight into the possible costs and benefits of operating the shift systems, acknowledgement must also be made of the shortcomings of that mode of research. Very often, because it is a real world situation, the researcher has little if any influence on many possibly confounding factors. Achieving and maintaining parity between comparison groups on all but the variables of interest is almost invariably compromised. It is, and has to be, research of a most pragmatic nature. This raises the question of laboratory studies examining eight hour versus 12 hour shift effects.

Extraneous influences such as temperature, workplace lighting, and work scheduling were controlled in a simulated control room study comparing alertness, mood, performance, and off duty sleep on eight and 12 hour night shifts reported by Baker. ${ }^{144}$ Commuting was eliminated, the exposure to daylight was limited during off duty hours, there were optimal off shift sleeping conditions, and there were no family or social responsibilities to attend to. The main findings of this study were as follows. The 12 hour group tended to show longer response times but greater accuracy than the eight hour group on several short duration cognitive performance tests. Subjects working eight hour shifts showed greater accuracy on one performance test. No differences emerged between the groups when operating a simulated process control, or in speed of responding to alarm signals. There were also no significant differences in terms of sleep quality or duration or in sleepiness measured by periodic multiple sleep latency tests, nor were there differences in self rated alertness, tiredness, or effort. Under controlled conditions neither cognitive performance, alertness, nor simulated work tasks were notably impaired on the 12 hour night shifts. Both eight hour and 12 hour night shift protocols showed a night of shift effect which suggested that subjects adapted to night duty after three to four shifts. This was reflected by improvement in subjective mood and alertness ratings, and speed of performance.

The general conclusions from this review must be that, on the basis of the evidence, especially that stemming from systematic applied research, it is not tenable to presume 12 hour shifts to have a systematic detrimental impact. Indeed, this view was strengthened by the evidence in papers presented at a recent international symposium on night and shiftwork held in Finland. Many papers replicated reports of there being advantages to 12 hour systems compared with eight hour rotas in terms of improvements to family and social life, no increases in accidents, injuries, or near miss incidents on 12 hour shifts, greater satisfaction with rotas, no major impact of longer shifts on sleep or sleepiness, greater ease of falling asleep, and feeling rested after sleep, little or no health outcome or differences in psychological wellbeing between the schedules and even a reduction of working hours on 12 hour shifts. ${ }^{80-83}$ The picture was not wholly positive, with some papers suggesting the need for caution in jobs with heavy physical demands, ${ }^{84}$ and others raising concerns about the exacerbating effects of workload, aging, and overtime on chronic exposure to longer work shifts. ${ }^{85}$ It is therefore evident that there are many questions still to be answered about the possible longer term effects of working 12 hour schedules. The obvious requirement in the present position is further well controlled, longitudinal research into the long term impact of 12 hour shift systems.

A summary table can be obtained from the corresponding author on request.

1 Folkard S, Monk T. Hours of work: temporal factors in work scheduling. Wiley: Chichester, 1985.

2 Scott AJ, Ladou J. Shiftwork: effects on sleep and health with recommendations for medical surveillance and screening. In: AJ Scott, ed. Occupational medicine: state of the art reviews: shiftwor

3 Waterhouse J, Folkard S, Minors D. Shiftwork, health and safety: an overview of the scientific literature 1978-90. safety: an overview of

4 Tepas DI, Mahan RP. The many meanings of sleep. Work Stress 1989;3:93-102.

5 Akerstedt T. Psychological and psychophysiological effects of shiftwork. Scand $\mathcal{F}$ Work Environ Health 1990;16:67-73.

6 Akerstedt T. Sleepiness at work: effects of irregular work hours. In: T Monk, ed. Sleep, sleepiness and performance. Chichester: Wiley, 1991:129-52.

7 Folkard S. Circadian performance rhythms: some practical and theoretical implications. Philos Trans R Soc Lond B Biol Sci 1990;327:543-53.

8 Fischer FM, Moreno CRC, Fernandez RL. Day and shiftworkes' leisure time. Ergonomics 1993;36:43-9.

9 Volger A, Ernst G, Nachreiner F, et al. Common free time of family members under different shift systems. Applied Ergonomics 1988;19:213-8.

10 Tepas DI. Flexitime, compressed workweeks and other alternative work schedules. In: Folkard S, Monk T, eds. Hours of work: temporal factors in work scheduling. Wiley: Chichester 1985:147-64.

11 Steward GV, Larsen JM. A four-day-three-day per week application to a continuous production operation. Management of Personnel Quarterly 1971;10:13-20.

12 Poor R, ed. 4-Days, 40-hours. Cambridge, MA: Bursk and Poor, 1970.

13 A Wedderburn, ed. Compressed working time. Dublin: European Foundation for the Improvement of Living and Working Conditions, 1996:7. (Bulletin of European Studies of Time No 10.)

13a Baker TL. Alertness, performance and off-duty sleep on 8-hour and 12-hour night shifts in a simulated continuous operations control room setting. NUREG/CR-6046. Washington, DC: Division of Systems Technology, Office of Nuclear Regula-
Ditrol rom setting. NUR tory Research, US Nuclear Regulatory Commission, 1995: tory Research, US Nuclear Regulatory

14 Underwood AB. What a 12-hour shift offers. Am 7 Nurs 1975;75:1176-8. 
15 Garong WL, Garong JM, Harrison ET. The 12-hour shift: better quality, lower cost. F Nurs Admin 1976;6:17-29.

16 Vik AG, Mackay RC. How does the 12-hour shift affect patient care? F Nurs Admin 1982;12:11-4.

17 Blanchflower S. Alternative rota systems. Nursing Times 1986;82:55-8.

18 Rosa R. Extended workshifts and excessive fatigue. Fournal of Sleep Research 1995:4:51-6.

19 Moores J. A meta-analytic review of the effects of compressed work schedules. Applied Human Resource Management Research 1990;1:12-8.

20 Vernon HM. The speed and adaptation of output to altered hours of work. Reports of the Industrial Fatigue Research hours of work. Reports of the Indu
Board. London: HMSO, 1920:6.

21 Osborne EE. The output of women workers in relation to hours of work in shell-making. Reports of the Industrial Fatigue Research Board. London: HMSO, 1919:2

22 Libre E. The good and the bad of 12-hour shifts. Registered Nurse 1975;38:47-52.

23 Thompson J. Rigour round the clock. Nursing Times 1989;85:21

24 Wallace M, Owens W, Levens M. Adaptation to twelve hour shifts. In: Costa G, Cesana G, Kogi K, et al, eds. Shiftwork: health, sleep and performance. Frankrurt am Main: Peter health, sleep
Lang, 1990.

25 Fields WL, Loveridge C. Critical thinking and fatigue: how do nurses on 8 and 12 hour shifts compare? Nursing Economics 1988;6:189-91.

26 Washburn MS. Fatigue and critical thinking on eight and twelve-hour shifts. Nursing Management 1991;22:80A-H.

27 Ugrovics A, Wright J. 12-Hour shifts: does fatigue undermine ICU nursing judgements? Nursing Management 1990;21:64A-G.

28 Mills ME, Arnold B, Wood CM. Core 12: a controlled study of the impact of 12-hour scheduling. Nurs Res 1983;32: 356-61.

29 Williamson AM, Gower CGI, Clarke BC. Changing the hours of shiftwork: a comparison of 8 and 12-hour shift hours of shiftwork: a comparison of 8 and 12-hour shift rosters in a

30 Duchon J, Keran C, Smith T. Extended workdays in an underground mine: a work performance analysis. Hum Factors 1994;36:258-69.

31 Wilson JT, Rose KM. The twelve hour shift in the petroleum and chemical industries of the United States and Canada: study of current experience. Philadelphia: Industrial Research Unit, The Wharton School, University of Pennsylvania, 1978. (Industrial research reports No 26.)

32 Johnston M, Pollard B, Manktelow A, et al. Stress and information processing in 8 and 12 -hour nursing shifts. The pychologist 1989 .

33 Smiley A, Moray NP. Review of 12-hour shifts at nuclear generating stations. Ottawa, Canada: Report to Atomic Energy erating stations. Ottawa, Canada: Report to A
Control Board, 1989. (Project No 2.131.1.)

34 Baker TL, Campbell SC, Linder KD, et al. Control room operator alertness and performance in nuclear power plants. Palo Alto, CA: February 1990. (Electric Power Research Institute Report NP-6748.)

35 Todd C, Reid N, Robinson G. The impact of 12-hour nursing shifts. Nursing Times 1991;87:47-50

36 Reid N, Robinson G, Todd C. The quantity of nursing care on wards working 8 and 12-hour shifts. Int 7 Nurs Stud 1993;30:403-13.

37 Bowers-Hutto C, Davis LL. 12-hour shifts: panacea or problem? Nursing Management 1989;20:56B-H.

38 Peacock B, Glube R, Miller M, et al. Police officers' responses to 8 and 12 hour shift schedules. Ergonomics 1983;26:479-93.

39 Parkes K. Sleep patterns, shiftwork and individual room operators. Ergonomics 1994;37:827-44.

40 Northrup HR. The twelve hour shift in the North American mini-steel industry. Fournal of Labor Research 1991;12:26178.

41 Lees R, Laundry B. Industrial accident experience of one company on 8 and 12 hour shift systems. Fournal of Occupational Medicine 1991;33:903-6.

42 Pollock C, Cross R, Taylor P. Influences of 12 versus 8 hour shiftwork on injury patterns. International Ergonomics Association. Ergonomie et Lieux de Travail 1994;5:19-21.

43 Ontario Hydro Report. Analysis of the impact of 12-hour shifts on human performance at Ontario Hydro Nuclear Generating Stations. Annual Report. Toronto: Ontario Hydro Technical Stations. Annual Report. Toronto: Ontario
and Training Services Division, 1986.

44 Lewis PM, Swaim DJ. Evaluation of a 12-hour day shift schedule. Proceedings of the Human Factors Society 30th Annual
Meeting. Dayton, Ohio: HFS, 1986;2:885-9.

45 Kelly RJ, Schneider MF. The twelve-hour shift revisited: recent trends in the electric power industry. F Hum Ergol (Tokyo) 1982;11:369-84.

46 Rosa R, Colligan M. Long workdays versus rest days: assessing fatigue and alertness with a portable performance battery. Hum Factors 1988;30:305-17.

47 Rosa R. Performance, alertness and sleep after 3-5 years of 12 h shifts: a follow up study. Work Stress 1991;5:107-16.

48 Rosa R, Bonnet MH. Performance and alertness on $8 \mathrm{~h}$ and $12 \mathrm{~h}$ rotating shifts at a natural gas facility. Ergonomics 1993; 36:1177-93.

49 Gould S. Safety considerations related to 12-hour shift schedules. Nuclear Safety 1989;30:103-5.

50 Lees R, Laundry B. Comparison of reported workplace morbidity in 8-hour and 12-hour shifts in one plant. Four nal of Social and Occupational Medicine 1989;39:81-4.
51 Frese M, Semmer N. Shiftwork stress and psychosomatic complaints: a comparison between workers in different hiftwork schedules, non-shiftworkers and former shiftworkers. Ergonomics 1986;29:99-114.

52 Tucker P, Barton J, Folkard S. Comparison of eight and 12 hour shifts: impacts on health, wellbeing and alertness during the shift. Occup Environ Med 1996;53:767-72.

53 Jaffe MP, Smolensky MH, Wun C. Sleep quality and physical and social wellbeing in North American petrochemical Texas, Health Sciences Centre, School of Public Health, PO Box 20186, Houston, Texas 77225, USA 1994.)

54 Knauth P. The design of shift systems. Ergonomics 1993;36: $15-28$.

55 Gadbois C, Prunier S. Douaniers en horaires atypiques: rythmes de vie et conditions de travail (Customs officers on unusual schedules: rhythms of life and working conditions). Rapport de Recherche 95p. Paris: EHPE, 1994.

56 Iskra-Golec I, Folkard S, Marek T, et al. Health, well-being and burnout of ICU nurses on 12 and 8 hour shifts. Work Stress 1996;10:251-6.

57 Chan OY, Gan SL, Yeo MH. Study on the health of female electronics workers on 12 hour shifts. Occup Med 1993;43: 143-8.

58 Hadjiova I, Mincheva L, Deyanov C. Cardiovascular strain in operators on 12-hour shifts. Rev Environ Health 1994;10:67-71.

59 Kundi $M$, Koller $M$, Stefan $\mathrm{H}$, et al. Attitudes of nurses towards 8-h and 12-h shift systems. Work Stress 1995;9: $134-9$.

60 Brief RS, Scala RA. Occupational exposure limits for novel work schedules. Am Ind Hyg Assoc F 1975;36:467-9.

61 Moretz S. Rotational shifts: are they harmful to workers' health? Occupational Hazards 1987;49:54-7.

62 Reynolds JL, Royster LH, Pearson RG. Hearing conservation programmes (HCPs): The effectiveness of one company's HCP in a 12-hour work shift environment. Am Ind Hyg Assoc F 1990;51:437-46.

63 Harma M. Individual differences in tolerance to shiftwork. Ergonomics 1993;36:101-10.

64 Withdrawn.

65 Conrad-Betschart $H$. Designing new shift schedules: participation as a critical factor for an improvement. In:
Costa G, Cesana G, Kogi K, et al, eds. Shiftwork: health, seep and performance. Frankrurt am Main: Peter Lang, 1990

66 Latack JC, Foster LW. Implementation of compressed work schedules: participation and job redesign as critical factors of employee acceptance. Personnel Psychology 1985;38:75-93.

67 Northrup HR, Wilson JT, Rose KM. The twelve-hour shift in the petroleum and chemical industries. Industrial Labour Relations Review 1979;32:312-26.

68 Smith L, Hammond T, Macdonald I, Folkard S. Twelve hour shifts are popular but are they a solution? International fournal of Industrial Ergonomics 1998;21:323-31.

69 Smith L, Barton J. Shiftwork and personal control. European Work and Organisational Psychologist 1995;4:101-20.

70 Suter P. Transition to 12-hour shifts: the process and the product. American Nuclear Society Annual Meeting. Boson, MA, USA. Transactions of the American Nuclear Society 1992;65:400.

71 Tepas DI. Condensed working hours: questions and issues. In: Costa G, Cesana G, Kogi K, et al, eds. Shiftwork: health, sleep and performance. Frankrurt am Main: Peter Lang, 1990.

72 Barton-Cunningham J. A compressed shift schedule: dealing with some of the problems of shiftwork. Fournal of Organizational Behaviour 1989;10:231-45.

73 Ivancevich JM. Effects of the shorter work week on selected satisfaction and performance measures. f Appl Psychol1974;59:717-21.

74 Nachreiner F, Frielingsdorf R, Romahn R, et al. Schichtarbeit bei kontinuierlicher produktion, Forschungsbericht No 141. Dortmund: Bundesanstaltfur Arbeitsschutzund Unfallforschung, 1975.

75 Jozef D. Morbidity and absenteeism rates for operators connected with duration of shift. Handbook of work and organizational psychology. Chichester: Wiley, 1984:283-9.

76 Keran CM, Duchon JC, Smith TJ. Older workers and longer workdays: are they compatible? International fournal of Industrial Ergonomics 1994;13:113-23.

77 Hoekstra F, Jansen B, Van Goudoever B. The compressed working week. Wyattville Road, Loughlinstown, Co Dublin, Ireland: European Foundation for the Improvement of Ireland: European Foundation for the

78 Baker K, Olson J, Morisseau D. Work practices, fatigue and nuclear power plant safety performance. Hum Factors 1994 ; 36:244-57.

79 Colligan MJ, Tepas DI. The stress of hours of work. Am Ind Hyg Assoc f 1986;47:686-95.

80 Smith PA, Wright BM, Mackey RW, et al. Results from a study of participative roster redesign: a change from slowly rotating 8 hour shifts to rapidly rotating 8 and 12 hour shifts. In: Harma $\mathrm{M}$, et al, eds. New challenges for the organisation of night and shiftwork [abstracts]. Helsinki, Finland: Finnish Institute of Occupational Health, 1997.

81 Lowden A, Akerstedt T, Kecklund G, et al. Shifting from an 8 hour to a 12 hour work schedule. In: Harma M, et al, eds. New challenges for the organisation of night and shiftwork [abstracts]. Helsinki, Finland: Finnish Institute of Occupational Health, 1997.

82 Tucker P, Smith L, Macdonald I, et al. Shift length as a determinant of on-shift alertness. In: Harma $\mathrm{M}$, et al, eds. New challenges for the organisation of night and shiftwork 
[abstracts]. Helsinki, Finland: Finnish Institute of Occupa-

83 Axelsson J, Kecklund G, Lowden A, et al. Alternating 8 and 12 hour shifts: differences in sleep and sleepiness. In: Harma M, et al, eds. New challenges for the organisation of night and shiftwork [abstracts]. Helsinki, Finland: Finnish Institute of Occupational Health, 1997

84 Rosa R, Bonnet M, Cole L. Work schedule and task factors in upper-extremity fatigue. In: Harma $\mathrm{M}$, et al, eds. New challenges for the organisation of night and shiftwork [abstracts]. Helsinki, Finland: Finnish Institute of Occupational Health, 1997 .

85 Bourdouxhe M, Queinnec Y, Granger D, et al. The effects of 20 years of rotating 12-hour shiftwork in petroleum refinery operators. In: Harma $M$, et al, eds. New challenges for the organisation of night and shiftwork [abstracts]. Helsinki, Finland: Finnish Institute of Occupational Health, 1997.

\section{Vancouver style}

All manuscripts submitted to Occup Environ Med should conform to the uniform requirements for manuscripts submitted to biomedical journals (known as the Vancouver style.)

Occup Environ Med, together with many other international biomedical journals, has agreed to accept articles prepared in accordance with the Vancouver style. The style (described in full in the $\mathcal{F} A M A[1]$ ) is intended to standardise requirements for authors, and is the same as in this issue.

References should be numbered consecutively in the order in which they are first mentioned in the text by Arabic numerals on the line in square brackets on each occasion the reference is cited (Manson[1] confirmed other reports[2][3][4][5]). In future references to papers submitted to Occup Environ Med should include: the names of all authors if there are three or less or, if there are more, the first three followed by et al; the title of journal articles or book chapters; the titles of journals abbreviated according to the style of Index Medicus; and the first and final page numbers of the article or chapter. Titles not in Index Medicus should be given in full.

Examples of common forms of references are:

1 International Committee of Medical Journal Editors. Uniform requirements for manuscripts submitted to biomed journals. fAMA 1993;269:2282-6.

2 Soter NA, Wasserman SI, Austen KF. Cold urticaria: release into the circulation of histmaine and eosinophil chemotactic factor of anaphylaxis during cold challenge. N Engl F Med 1976;294:687-90.

3 Weinstein L, Swartz MN. Pathogenic properties of invading micro-organisms. In: Sodeman WA Jr, Sodeman WA, eds. Pathologic physiology, mechanisms of disease. Philadel phia: W B Saunders, 1974:457-72.
ef disease. Philadel- 